February - 2021

\title{
First-Generation Students in Distance Education Program: Family Resources and Academic Outcomes
}

Michael R. Brubacher ${ }^{1}$ and Fortunate T. Silinda ${ }^{2}$

1 University of Johannesburg, 2 University of South Africa

\begin{abstract}
Distance education students have less access to classmates as a social resource and may, therefore, rely more on family members for support. However, first-generation students, or students who are the first in their family to attend university, may lack the academic resources that family members can provide. Overall, first-generation students in distance education programs may be at particular risk of lacking the necessary social capital to thrive in university. This study investigated whether two family resource variables-providing guidance about university and expressing supportive attitudes toward universityvaried across generation status among distance education students. The study also investigated whether these family resource variables predicted students' academic adjustment and academic persistence. A sample of 224 undergraduate, distance education students in South Africa completed an online survey. First-generation students $(n=60)$ reported receiving less university guidance from family members compared to continuing-generation students. In addition, receiving university guidance predicted students' academic adjustment. The results suggest that university guidance from family members may serve as a protective factor against potential challenges that can impact students' academic adjustment, a protective factor that first-generation students are less likely to have.
\end{abstract}

Keywords: first-generation students, distance education, social capital, academic adjustment, academic persistence 


\section{Introduction}

Distance education has enabled academic institutions to offer programs to an increasing number of students. The ease of access and convenience that distance education affords (e.g., students are not required to move away from family or employment to attend university) allows students to enrol who would not otherwise be able to do so (Hart, 2012; Jaggars, 2014; Qayyum \& Zawacki-Richter, 2019; Willging \& Johnson, 2009). One population of students, in particular, may have benefited from the access that distance education provides: first-generation students who are the first in their family to attend university.

However, while distance education programs may increase access, first-generation students may have poorer academic experiences and outcomes compared to their continuing-generation peers. Research on traditional, classroom-based university students has found that first-generation students have a harder time understanding university culture, understanding faculty expectations, and believing in their own academic abilities (Collier \& Morgan, 2008; Ishitani, 2003; Metcalf \& Wiener, 2018; Pascarella, Pierson et al., 2004; Stephens et al., 2012). These problems may be exacerbated in distance education programs, where there are higher dropout rates, in general, compared to classroom-based programs (Simpson, 2013).

One explanation for poor academic outcomes among first-generation students is that they have less social capital to draw upon when engaging in the university environment compared to other students (e.g., Collier \& Morgan, 2008; Wainwright \& Watts, 2021). Notwithstanding the importance of university staff, for undergraduate students, social capital can include family members and university friends and classmates who possess knowledge about university life or who can simply provide moral support and encouragement. Indeed, research on classroom-based university students has found that they view both family members and university classmates as valuable sources of social support for dealing with the uncertainties and challenges of university life (El-Ghoroury et al., 2012; Pillay \& Ngcobo, 2010).

Although family and friends can both be social resources, some studies on classroom-based university students have found that support from classmates was a stronger predictor of academic outcomes (Dennis et al., 2005; Friedlander et al., 2007). In distance education, however, access to university classmates is more limited, and feeling isolated and removed from one's classmates is one of the reasons why students in distance education drop out of programs (Hart, 2012; Mittelmeier et al., 2019; Willging \& Johnson, 2009). With more limited social support from classmates, distance education students may benefit more from family members as a social resource. However, since the parents of first-generation students do not have university experiences to draw upon, the extent of their support may also be limited.

The present study compared the family resources of first-generation and continuing-generation students in distance education programs. The study also analyzed whether these family resources predicted academic outcomes. Two family resource variables were considered: university guidance, which addresses whether family members can provide the student specific advice regarding university matters; and supportive attitudes, which pertains to whether family members support the student's pursuit of higher education. The academic outcome variables considered were the student's academic adjustment, in terms of keeping up with the demands of academic tasks and performing them well 
(Feldt et al., 2011); and academic persistence, in terms of the intent to continue studying in a chosen program and to complete the degree (Pascarella \& Terenzini, 1980).

Family members can be a source of social capital if they can offer advice or answer specific questions about the university context. Unfortunately, when a student's family members have not attended university themselves, they may lack understanding of the university context and be less able to provide guidance. Priebe et al.'s (2008) qualitative study of first-generation students found that the parents may have difficulty offering guidance on university matters, such as completing applications, selecting programs, and obtaining financial aid. The present study used a quantitative approach to compare the level of university guidance first-generation students and continuing-generation students received from family members. The authors anticipated that first-generation students would report having received less university guidance from family members compared to continuing-generation students.

Family members can also be a social resource more generally, by expressing positive and affirmative attitudes about the student's pursuit of higher education. Research findings on first-generation students in this regard are somewhat mixed. On the one hand, in several qualitative studies, first-generation students reported receiving positive messages from their parents regarding education, in general, along with the pursuit of higher education, in particular. These messages included valuing education from elementary school onward, encouraging the pursuit of higher degrees, and expressing pride about the student's academic pursuits and achievements (Gofen, 2009; Hebert, 2018; Irlbeck, Adams et al., 2014). On the other hand, in some studies, first-generation students reported receiving discouraging messages from their parents, including not expecting that the student would enrol in university, valuing a focus on family instead of academic pursuits, or considering a university degree devoid of value or practical purpose (Priebe et al., 2008). It was, therefore, unclear at the outset of the study whether the attitudes of first-generation students' family members would be less or more supportive or the same as the attitudes of continuing-generation students' family members.

The present study further investigated whether family members' university guidance and supportive attitudes would predict the academic adjustment and academic persistence of distance education students. Prior research has touched upon the relationship between family resources and academic outcomes. For example, research on both distance education students and classroom-based students found that general family support (e.g., "my family cares about me") correlated with academic adjustment (Rodriguez et al., 2017) as well as academic persistence (Ceglie \& Settlage, 2016; Park \& Choi, 2009). However, these studies did not determine whether specific types of family support (i.e., university guidance and supportive attitudes about university, in particular) correlated with these outcomes. Additional research on classroom-based students found that university guidance and supportive attitudes about university were both related to academic factors, such as higher enrolment, reduced college stress, and reduced loneliness (Dorrance Hall, et al., 2017; Gofen, 2009; Hebert, 2018; Irlbeck et al., 2014). Yet, these studies did not specifically consider academic adjustment and academic persistence, and did not focus on distance education students.

The authors anticipated that university guidance, which includes advice about navigating university environments, would be a stronger predictor of academic adjustment, compared to supportive attitudes. They also anticipated that supportive attitudes, which include the affirmation of academic pursuits, would be a stronger predictor of academic persistence, compared to university guidance. 


\section{Methods}

\section{Study Participants and Procedures}

Undergraduate students at a distance education university in South Africa voluntarily participated in the study and completed a survey questionnaire online. An online description of the study was read by 376 students. Of these students, 224 students completed the study survey. The final sample comprised $54 \%$ female and $46 \%$ male students, who ranged in age from 19-years-old to 59-years-old $(M=33.70$, $S D=9.00$ ). Based on the racial categories currently used in South Africa, $52 \%$ of the participants were Black, 32\% White, $9 \%$ Coloured, and $7 \%$ Indian. Most of the students regarded themselves as middle class. $18 \%$ of the students regarded themselves as lower-middle class, $29 \%$ as middle class, $14 \%$ as upper-middle class; and $29 \%$ of the students regarded themselves as working class, $9 \%$ as poor, and $1 \%$ as wealthy.

The students were enrolled in the faculties of human sciences (25\%), law (20\%), agriculture and environmental sciences (13\%), economics and management sciences (13\%), science, engineering, and technology (13\%), accounting (8\%), and education (8\%). $41 \%$ of the participants were in their 1st year of university, $19 \%$ were in their 2 nd year, $26 \%$ were in their 3 rd year, and $14 \%$ were in their 4 th year. Data collection occurred at the beginning of the second semester of the academic year. Ethical approval for the study was granted by an institutional review board at the University of South Africa.

\section{Survey Measures}

\section{Generation Status}

Participants were asked to respond "yes" or "no" to a number of statements to determine whether their family members attended/graduated from university. The survey items were "I have a primary caretaker (i.e., a person who looked after me when growing up) who attended university but did not graduate," "I have a primary caretaker (i.e., a person who looked after me when growing up) who graduated from university," "I have a family member (i.e., a person other than a caretaker) who attended university but did not graduate," and "I have a family member (i.e., a person other than a caretaker) who graduated from university." Based on their responses, participants were assigned a generation status group, as follows,

- If a participant had a primary caretaker who graduated from university, they were assigned to the caretaker-graduated group.

- If a participant had a non-caretaker family member who graduated from university, they were assigned to the non-caretaker-graduated group.

- If a participant had a caretaker who attended university but did not graduate, they were assigned to the caretaker-attended group.

- If a participant had a non-caretaker family member who attended university but did not graduate, they were assigned to the non-caretaker-attended group.

- If a participant chose "no" in response to all of the generation status items, they were assigned to the first-generation group. 
Close to a third of the participants $(27 \%, n=60)$ were first-generation students; $42 \%(n=94)$ of students were in the non-caretaker-graduated group, $26 \%(\mathrm{n}=58)$ were in the caretaker-graduated group, $3 \%(n=7)$ were in the caretaker-attended group, and $2 \%(n=5)$ were in the non-caretakerattended group. Since a very small number of participants were in the caretaker-attended and the noncaretaker-attended groups, these groups were not included in the analyses. Therefore, the analyses began with three generation status groups: first-generation, non-caretaker-graduated, and caretakergraduated groups.

\section{University Guidance}

Guidance from family members about university was measured using four items: "I have a family member who gives me advice about university," "I have a family member who can answer questions that I have about university," "I have a family member who helps me with the challenges of university life," "My family is a valuable resource for me to talk to about university." Responses were provided on a 5-point Likert scale that ranged from "strongly disagree" to "strongly agree." Cronbach's alpha for the scale was .93.

\section{Supportive Attitudes}

Family attitudes about pursuing a university degree were measured using four items: "In general, my family supports the idea of me going to university," "In general, my family is proud that I am going to university," "In general, my family wants me to graduate from university," and "I can easily talk to my family about university life." Responses were provided on a 5-point Likert scale that ranged from "strongly disagree" to "strongly agree." Cronbach's alpha for the scale was .90.

\section{Academic Adjustment}

Adjustment to the academic tasks and responsibilities of a university education were measured using five items: "I have been keeping up to date on my academic work," "I prepare for my assignments regularly," "I really feel I am using my time well in university," "I am satisfied with the level at which I am performing academically," and "I am enjoying my academic work at university." Responses were provided on a 5-point Likert scale that ranged from "strongly disagree" to "strongly agree." Cronbach's alpha for the scale was .83 .

\section{Academic Persistence}

The academic persistence of the students was measured using three items: "I intend to continue studying in my field," "I intend to get a Bachelor's degree in my field of study," and "I am sure that I want to continue with my education in my current field of study." Responses were provided on a 5-point Likert scale that ranged from "strongly disagree" to "strongly agree." Cronbach's alpha for the scale was .80 .

\section{Data Analyses}

Data analyses were conducted using structural equation modelling (SEM) to test the study hypotheses. Regarding generation status and family resources, the authors anticipated that first-generation students would report less university guidance compared to continuing-generation students, while no hypothesis was made regarding generation status and family attitudes. Regarding family resources and academic outcomes, the authors anticipated that university guidance would be a stronger predictor of academic adjustment than would supportive attitudes, while supportive attitudes would be a stronger predictor of academic persistence than would university guidance. 
Within the path model, generation status served as an independent variable, the two family resource variables served as mediators, and the two academic outcomes served as outcome variables. However, since generation status was measured using an ordinal scale, the use of dummy variables would have been required within the model. Preliminary analyses were, therefore, conducted to determine whether any of the generation status categories could be combined.

\section{Preliminary Analyses}

A one-way analysis of variance (ANOVA) was conducted for each family resource variable, with generation status as the independent variable. Results show a significant difference between generation status categories for university guidance, $F(2,226)=17.93, p<.001$, but not for supportive attitudes $F(2,226)=0.86, p=.425$. A Tukey post-hoc test was conducted to determine how university guidance varied across the generation status categories. Results show that university guidance was significantly lower for the first-generation group $(M=2.37, S D=1.24)$ compared to the non-caretaker-graduated group $(M=3.30, S D=1.40, p<.001)$ and the caretaker-graduated group $(M=3.73, S D=1.24, p<$ .oo1). The difference between the non-caretaker-graduated group and the caretaker-graduated group was not significant $(p=.097)$.

Overall, no differences were found between the non-caretaker-graduated group and the caretakergraduated group regarding both family resource variables. In addition, the non-caretaker-graduated group and the caretaker-graduated group are conceptually similar in that they both refer to having a family member who graduated from university. Therefore, in order to simplify the SEM, the noncaretaker-graduated group and the caretaker-graduated group were combined, making the generation status variable a dichotomous variable, labelled as first-generation students and continuing-generation students. Descriptive statistics were used to present the results of the SEM.

\section{Results}

Results of the SEM conducted to test the proposed relationships between family resources and academic outcomes are presented Figure 1 and Table 1 . The model had adequate fit, $\chi^{2}(122)=259.92, p<.001$, comparative fit index $(\mathrm{CFI})=.94$, root-mean-square error of approximation (RMSEA) $=.07$, and standardized root-mean-square residual $(\mathrm{SRMR})=.06$. 


\section{Figure 1}

Structural Equation Model (SEM) of Family Resources and Academic Outcomes

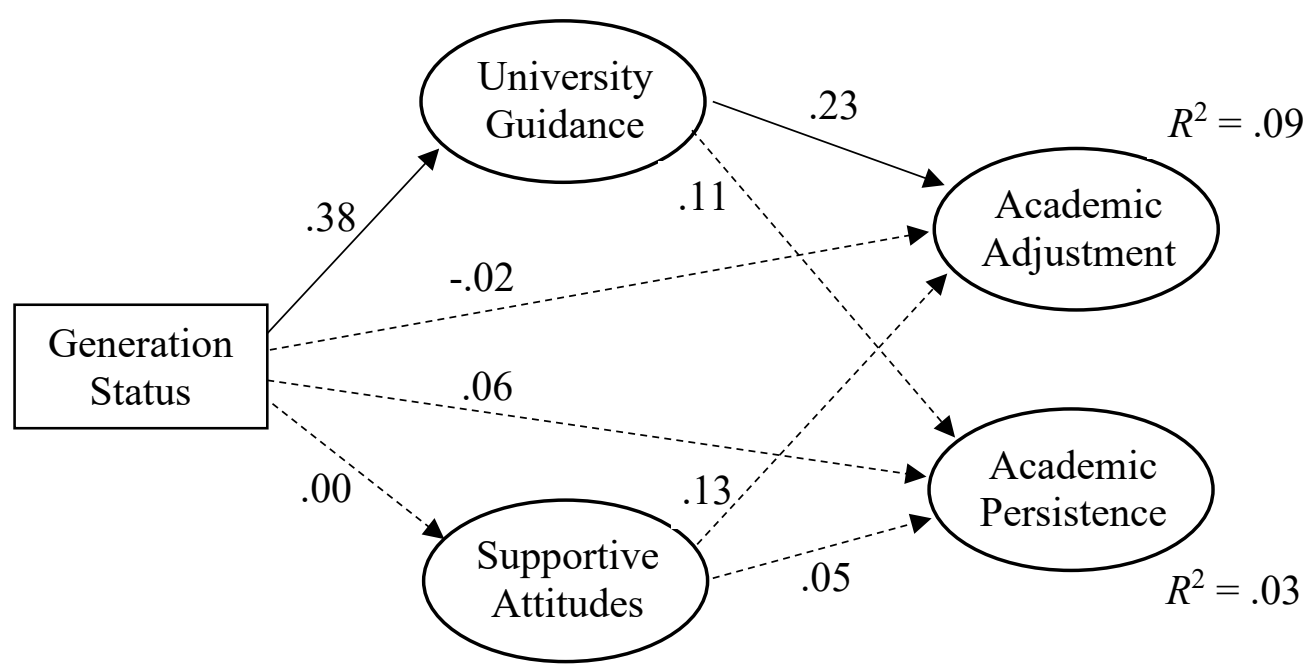

Note. The measurement model was excluded to improve clarity. Solid lines represent significant paths $(p<.05)$. Path coefficients are standardized. Generation status was coded as o for first-generation and 1 for continuing-generation. Multiple correlation squared $\left(R^{2}\right)=$ explained variance.

\section{Table 1}

Means, Standard Deviations, and Correlations of Family Resources and Academic Outcomes

$\begin{array}{llllll}\text { Variable } & M(S D) & 1 & 2 & 3 & 4\end{array}$

1. Generation status

2. Supportive attitudes $\quad 4.63(.71) \quad$.oo

3. University guidance $\quad 3.17(1.41) \quad .36^{*} \quad .43^{*}$

4. Academic adjustment $\quad 4.13(.77) \quad .12 \quad .21^{*} \quad .30^{*}$

5. Academic persistence $\quad 4.63(.73) \quad .07 \quad .13^{*} \quad .11 \quad .33^{*}$

Note. Generation status was coded as o for first-generation and 1 for continuing-generation.

${ }^{*} p<.05$.

Results show that, as expected, generation status predicted university guidance: First-generation students received less guidance from family members than continuing-generation students. In addition, for distance education students in general, university guidance predicted academic adjustment. Overall, the predictor variables in the model accounted for $9 \%$ of the variance in academic adjustment. Generation status did not predict family members' supportive attitudes. However, a hypothesis 
regarding supportive attitudes had not been established a priori, as results from previous qualitative studies were mixed: some first-generation students reported that family members' attitudes were supportive while others reported that that family members' attitudes were discouraging (Gofen, 2009; Hebert, 2018; Irlbeck et al., 2014; Priebe et al., 2008). In this study, supportive attitudes were quantitively compared between first-generation students and continuing-generation students, and a significant difference was not found between the student groups. Finally, despite expectations that supportive attitudes, in particular, would predict academic persistence, findings show that none of the variables were significant predictors of academic persistence.

Considering that generation status predicted university guidance and university guidance predicted academic adjustment, a significant test of the indirect effect was conducted. The test revealed a significant indirect effect between generation status and academic adjustment, mediated by university guidance. The unstandardized indirect effect was .13 and standard effect $(S E)=.06, p=.017$. All other indirect effects were also tested but were not significant $(p>.100)$.

\section{Discussion}

Social capital can be an important resource for undergraduate students to succeed within the university context. For distance education students, who have less access to classmates, family members can become particularly valuable. However, distance education students who are also first-generation students may lack this resource as well. The present study explored whether the university guidance of family members and their supportive attitudes toward higher education varied across generation status. The study also considered whether these family resources predicted the academic adjustment and academic persistence of distance education students.

Results show that first-generation students received less university guidance from family members compared to continuing-generation students. Furthermore, for distance education student in general, university guidance was a significant predictor of academic adjustment though not of academic persistence. As such, first-generation students were less likely to receive university guidance from family members, potentially limiting their academic adjustment. However, since the relationship between university guidance and academic adjustment was tested using a correlational design, causality cannot be determined. Not all undergraduate students necessarily rely on family members for advice or need family members to help them adjust to university (Friedlander et al., 2007). However, the indirect effect of generation status on academic adjustment, mediated by university guidance, indicates that the university experience of family members can be a resource for distance education students.

University guidance from family members may serve as a protective factor that distance education students can rely on when experiencing academic difficulties; however, the results show that firstgeneration students tend to lack the protective element that university guidance affords. Future research is needed to investigate the conditions in which students seek university guidance and how this guidance assists in academic adjustment. Further research should specifically explore whether university guidance primarily operates as a protective factor against certain risks, and if so, in what scenarios and for whom (see Luthar et al., 2000; Makoe \& Nsamba, 2019). 
The study found that the supportive attitudes of family members did not vary across generation status. Although, as previous studies have shown, some first-generation students experience negative attitudes from family members about higher education (e.g., Priebe et al., 2008), such attitudes did not occur to a greater extent among first-generation students compared to continuing-generation students. As such, the supportive attitudes available to first-generation students are not necessarily different from those available to continuing-generation students. However, participation in the present study was limited to students enrolled in a specific university. Individuals who are not enrolled in a university but are considering enrolment, and would be the first in their family to do so, may have family members who are less supportive of higher education. Furthermore, previously-enrolled students who dropped out of their program may also have family members who hold less supportive attitudes and may be more likely to be first-generation students. Among students who are enrolled in a university, the study found no differences in the supportive attitudes of family members across generation status. In addition, the study found that supportive attitudes were not a significant predictor of either academic adjustment or academic persistence.

Regarding the potential relationships between generation status and the other four variables in the model, only one relationship was statistically significant: the relationship between generation status and university guidance (although there was also a significant indirect effect of generation status on academic adjustment). This finding is consistent with prior research that found that first-generation students sometimes have poorer academic outcomes than other students but only in certain domains, with effect sizes that are often small (see Pascarella et al., 2004). However, additional research is needed to further identify the deficits of first-generation students in distance education programs (e.g., absence of certain protective factors, such as university guidance) and determine how these deficits impact academic outcomes.

Knowing the unique circumstances of first-generation students can inform the development of resources for distance education that would be particularly beneficial for first-generation students. For example, first-generation students may benefit from university-level social resources that they can rely on when they experience university-related challenges (e.g., Kara \& Can, 2019). Distance education universities could develop student-based social platforms through which students could receive advice about university. While such forums often exist for individual courses, they could also be developed and managed at the university level. Instead of posting questions about course content, students could post questions about university life in general (e.g., time management), to be answered by other students or by university staff.

Finally, the non-significant difference in university guidance available to students in the caretakergraduated group and the students in the non-caretaker-graduated group (see Preliminary Analyses) requires consideration. While, both groups could be regarded as continuing-generation groups, because they both reference a family member who graduated from university, it is possible that students in the caretaker-graduated group reported a higher degree of university guidance compared to those in the non-caretaker-graduated group. This possibility is based on the assumption that students could receive more advice from their parents or primary caretakers than from extended family members. However, this assumption may not be true in all cultural contexts. For example, Mylonas and colleagues (2001) found that while the level of communication with parents is relatively stable across cultures, the level of communication with extended family members is more varied; it can range from being somewhat low in some cultures to being comparable to primary caretakers in others. 
The present study took place in South Africa where no significant difference was found in university guidance between the caretaker-graduated group and the non-caretaker-graduated group. However, differences between these two groups may exist in other cultures, where extended family members play a smaller role in offering guidance compared to primary caretakers. Additional research should be conducted to determine how cultural factors influence the availability of family resources, focusing on nuclear and extended families, in order to develop a more nuanced conceptualization of first-generation status.

In conclusion, distance education is expanding and more students are the first in their families to attend higher education. Unfortunately, distance education programs have lower graduation rates compared to traditional, classroom-based programs; and first-generation students have poorer academic outcomes compared to continuing-generation students. Further research is needed to better understand the experiences of first-generation students in distance education programs. This study found that first-generation students receive less university guidance from family members than continuing-generation students, which may have negative impact on how well distance education students adjust to the academic demands of an undergraduate degree. 


\section{References}

Ceglie, R. J., \& Settlage, J. (2016). College student persistence in scientific disciplines: Cultural and social capital as contributing factors. International Journal of Science and Mathematics Education, 14, 169-186. https://doi.org/10.1007/s10763-014-9592-3

Collier, P. J., \& Morgan, D. L. (2008). "Is that paper really due today?”: Differences in first-generation and traditional college students' understandings of faculty expectations. Higher Education, 55, 425-446. https://doi.org/10.1007/s10734-007-9065-5

Dennis, J. M., Phinney, J. S., \& Chuateco, L. I. (2005). The role of motivation, parental support, and peer support in the academic success of ethnic minority first-generation college students. Journal of College Student Development, 46(3), 223-236. https://doi.org/10.1353/csd.2005.0023

Dorrance Hall, E., McNallie, J., Custers, K., Timmermans, E., Wilson, S. R., \& Van den Bulck, J. (2017). A cross-cultural examination of the mediating role of family support and parental advice quality on the relationship between family communication patterns and first-year college student adjustment in the United States and Belgium. Communication Research, 44(5), 638-667. https://doi.org/10.1177/0093650216657755

El-Ghoroury, N. H., Galper, D. I., Sawaqdeh, A., \& Bufka, L. F. (2012). Stress, coping, and barriers to wellness among psychology graduate students. Training and Education in Professional Psychology, 6(2), 122-134. https://doi.org/10.1037/a0028768

Feldt, R. C., Graham, M., \& Dew, D. (2011). Measuring adjustment to college: Construct validity of the student adaptation to college questionnaire. Measurement and Evaluation in Counseling and Development, 44(2), 92-104. https://doi.org/10.1177/0748175611400291

Friedlander, L. J., Reid, G. J., Shupak, N., \& Cribbie, R. (2007). Social support, self-esteem, and stress as predictors of adjustment to university among first-year undergraduates. Journal of College Student Development, 48(3), 259-274. https://doi.org/10.1353/csd.2007.0024

Gofen, A. (2009). Family capital: How first-generation higher education students break the intergenerational cycle. Family Relations: Interdisciplinary Journal of Applied Family Science, 58(1), 104-120. https://doi.org/10.1111/j.1741-3729.2008.00538.x

Hart, C. (2012). Factors associated with student persistence in an online program of study: A review of the literature. Journal of Interactive Online Learning, 11(1), 19-42. Retrieved from https://www.ncolr.org/jiol/issues/pdf/11.1.2.pdf

Hebert, T. P. (2018). An examination of high-achieving first-generation college students from lowincome backgrounds. Gifted Child Quarterly, 62(1), 96-110. https://doi.org/10.1177/0016986217738051

Irlbeck, E., Adams, S., Akers, C., Burris, S., \& Jones, S. (2014). First generation college students: Motivations and support systems. Journal of Agricultural Education, 55(2), 154-166. https://doi.org/10.5032/jae.2014.02154 
Ishitani, T. T. (2003). A longitudinal approach to assessing attrition behaviour among first-generation students: Time-varying effects of pre-college characteristics. Research in Higher Education, 44, 433-449. https://doi.org/10.1023/A:1024284932709

Jaggars, S. S. (2014). Choosing between online and face-to-face courses: Community college student voices. American Journal of Distance Education, 28(1), 27-38.

https://doi.org/10.1080/08923647.2014.867697

Kara, M., \& Can, G. (2019). Master's students' perceptions and expectations of good tutors and advisors in distance education. The International Review of Research in Open and Distributed Learning, 2O(2), 162-179. https://doi.org/10.19173/irrodl.v20i2.3674

Luthar, S. S., Cicchetti, D., \& Becker, B. (2000). The construct of resilience: A critical evaluation and guidelines for future work. Child Development, 71(3), 543-562. https://doi.org/10.1111/1467$\underline{8624.00164}$

Makoe, M., \& Nsamba, A. (2019). The gap between student perceptions and expectations of quality support services at the University of South Africa. American Journal of Distance Education, 33(2), 132-141. /https://doi.org/10.1080/08923647.2019.1583028,

Metcalf, D. A., \& Wiener, K. K. K. (2018). Academic self-efficacy in a 21st-century Australian university: Strategies for first-generation students. Higher Education Research \& Development, 37(7), 1472-1488. https://doi.org/10.1080/07294360.2018.1484705

Mittelmeier, J., Rogaten, J., Sachikonye, M., Gunter, A., Prinsloo, P., \& Rienties, B. (2019). Understanding the adjustment of first-year distance education students in South Africa: Factors that impact students' experiences. The International Review of Research in Open and Distributed Learning, 20(3), 18-38. https://doi.org/10.19173/irrodl.v20i4.4101

Mylonas, K., Bafiti, T., Poortinga, Y. H., Christakopoulou, S., Kagitcibasi, C., Kwak, K., Ataca, B., Berry, J., Orung, S., Sunar, D., Charalambous, N., Goodwin, R., Wang, W. Z., Angleitner, A., Stepanikova, I., Pick, S., Givaudan, M., Zhuravliova-Gionis, I., Konantambigi, R., Gelfand, M. J., Marinova, V., McBride-Chang, C., and Kodic, Y. (2001). Functional relationships in the nuclear and extended family: A 16-culture study. International Journal of Psychology, 36(5), 289-300. https://doi.org/10.1080/00207590143000045

Park, J., \& Choi, H. J. (2009). Factors influencing adult learners' decision to drop out or persist in online learning. Educational Technology \& Society, 12(4), 207-217. Retrieved from https://www.jstor.org/stable/10.2307/jeductechsoci.12.4.207

Pascarella, E. T., Pierson, C. T., Wolniak, G. C., \& Terenzini, P. T. (2004). First-generation college students: Additional evidence on college experiences and outcomes. The Journal of Higher Education, 75(3), 249-284. https://doi.org/10.1080/00221546.2004.11772256

Pascarella, E. T., \& Terenzini, P. T. (1980). Predicting freshman persistence and voluntary dropout decisions from a theoretical model. Journal of Higher Education, 51(1), 60-75. https://doi.org/10.2307/1981125 
Pillay, A. L., \& Ngcobo, H. S. B. (2010). Sources of stress and support among rural-based first-year university students: An exploratory study. South African Journal of Psychology, 4O(3), 234240. https://doi.org/10.1177/008124631004000302

Priebe, L. C., Ross, T. L., \& Low, K. W. (2008). Exploring the role of distance education in fostering equitable university access for first generation students: A phenomenological survey. The International Review of Research in Open and Distance Learning, 9(1), 1-12. https://doi.org/10.19173/irrodl.vgi1.452

Qayyum, A., \& Zawacki-Richter, O. (2019). The state of open and distance education. In O. ZawackiRichter, \& A. Qayyum (Eds.), Open and distance education in Asia, Africa and the Middle East (pp. 125-140). Springer. https://doi.org/10.1007/978-981-13-5787-9 14

Rodriguez, M. S., Tinajero, C., \& Paramo, M. F. (2017). Pre-entry characteristics, perceived social support, adjustment and academic achievement in first-year Spanish university students: A path model. Journal of Psychology, 151(8), 722-738.

https://doi.org/10.1080/00223980.2017.1372351

Simpson, O. (2013). Student retention in distance education: Are we failing our students? Open Learning, 28(2), 105-119. https://doi.org/10.1080/02680513.2013.847363

Stephens, N. M., Fryberg, S. A., Markus, H. R., Johnson, C. S., \& Covarrubias, R. (2012). Unseen disadvantage: How American universities' focus on independence undermines the academic performance of first-generation college students. Journal of Personality and Social Psychology, 102(6), 1178-1197. https://doi.org/10.1037/a0027143

Wainwright, E., \& Watts, M. (2021). Social mobility in the slipstream: First-generation students' narratives of university participation and family. Educational Review, 73(1), 111-127. Advance online publication. https://doi.org/10.1080/00131911.2019.1566209

Willging, P. A., \& Johnson, S. D. (2009). Factors that influence students' decision to drop-out of online courses. Journal of Asynchronous Learning Networks, 13(3), 115-127. http://dx.doi.org/10.24059/olj.v13i3.1659

\section{Athabasca} University

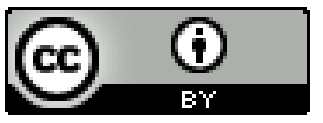

